\title{
Improving the Physical and Mechanical Performance of Laminated Wooden Structures by Low-Temperature Plasma Treatment
}

\author{
Ruslan Rushanovich Safin (D), Ruslan Khasanshin, Nour Galyavetdinov (D), Regina Salimgaraeva *, \\ Shamil Mukhametzyanov (D), Albina Safina and Natalia Kraysman
}

check for

updates

Citation: Safin, R.R.; Khasanshin, R. Galyavetdinov, N.; Salimgaraeva, R.; Mukhametzyanov, S.; Safina, A.;

Kraysman, N. Improving the Physical and Mechanical Performance of Laminated Wooden Structures by Low-Temperature Plasma Treatment. Coatings 2021, 11, 918. https:// doi.org/10.3390/coatings11080918

Academic Editor: Marko Petric

Received: 30 June 2021

Accepted: 28 July 2021

Published: 30 July 2021

Publisher's Note: MDPI stays neutral with regard to jurisdictional claims in published maps and institutional affiliations.

Copyright: (c) 2021 by the authors. Licensee MDPI, Basel, Switzerland. This article is an open access article distributed under the terms and conditions of the Creative Commons Attribution (CC BY) license (https:// creativecommons.org/licenses/by/ $4.0 /)$.
The Department of Architecture and Design of Wood Products, Kazan National Research Technological University, Karl Marx 68, 420015 Kazan, Russia; cfaby@mail.ru (R.R.S.); rusl2881@mail.ru (R.K.); nour777@mail.ru (N.G.); joker775.87@mail.ru (S.M.); alb_saf@mail.ru (A.S.); n_kraysman@mail.ru (N.K.)

* Correspondence: reginka.danilova@mail.ru
Abstract: This paper considers the effect of RF plasma on wood in improving the adhesion of binders to wood by increasing its surface wettability. Our study reveals that radiofrequency (RF) plasma treatment causes a greater than threefold decrease in the marginal wetting angle of wood. The greatest effect is achieved in RF plasma treatment in argon, which is on average $5 \%$ greater than that of RF plasma treatment in air or in propane/nitrogen mixture. In addition, the power of the RF plasma torch has the greatest influence, and the main influence comes from the voltage applied to the RF plasma torch; current does not have such a significant effect. To achieve a significant effect, the duration of exposure should be at least $5 \mathrm{~min}$, with a total power of $4.05 \mathrm{~kW}$. Studies have been conducted to determine the adhesive strength of wood. An increase in the strength of laminated beams made from RF-treated bars in relation to control samples was found. The greatest impact on the adhesion strength was revealed when using PVA-based glue, compared with the use of polyurethane-based adhesives and urea-formaldehyde resin.

Keywords: wood; RF treatment; adhesion; wettability; adhesive joint

\section{Introduction}

Today, of all the existing materials, wood remains one of the most environmentally friendly and widespread natural building materials. The most promising area of application is large-span laminated wooden structures. Today, the range of manufactured products includes beams, trusses, frames, and arch-type, large-span laminated wooden structures. The maximum unsupported span of modern wooden structures is $150 \mathrm{~m}$. As a rule, buildings and structures erected using this technology are assembled quickly: the entire necessary set of factory-prefabricated parts is supplied to the construction site. As practice shows today, the use of large-span laminated wooden structures reduces the cost of covering construction by almost one-third in comparison with more traditional structures made of metal and reinforced concrete. Moreover, the erection of structures made of laminated wood is much cheaper, since wooden structures are lightweight, which reduces the requirements for both the load-carrying capacity of mounting devices and the load-bearing capacity of building foundations and the substructure soil.

However, despite all of these existing positive aspects, wood itself, as a material, has many disadvantages that limit its applicability to one degree or another, including in the production of large-span laminated wooden structures. Among the significant disadvantages of solid wood-especially its inexpensive types-are its low operational, physical, and mechanical properties, as well as the ability of wood to change its geometric dimensions due to changes in humidity. In addition, a number of wood species have poor adhesion to some adhesives, which is also a significant disadvantage, since this characteristic is important in the production of large-span laminated wooden structures, where the quality of the adhesive layer plays an important role. As a result of all of the 
above, it can be concluded that increasing the physical and mechanical qualities of lowgrade wood and increasing its adhesive qualities should be considered among the main issues to be addressed in the construction industry [1-4].

To date, the most common methods for improving the properties of wood are impregnation with inorganic and organic chemical compositions. In this case, the main process requirement is wood impregnation depth, the determining factor for which, with capillary technologies, is the wettability of the material.

In this regard, methods of modifying the surface of wood materials in order to increase wettability attract the attention of a large number of researchers [5-10]. Here electrophysical methods come to the fore, among which radiofrequency plasma treatment stands out.

The first studies of plasma treatment were conducted back in the 1960s. However, in recent years, "cold" plasma surface treatment has undergone major changes [11]. Especially interesting in this regard are studies on the modification of the surfaces of polymer materials, which currently has many industrial applications (e.g., improving the adhesion of paints and resins, improving the binding of filler with a polymer matrix in composites, etc.).

Modification with radiofrequency plasma is able to solve a wide range of problems: removal of residual stresses, changing the surface roughness, removal of relief and fractured layers, increasing corrosion resistance, activating the surface of the material for finishing, increasing water absorption, etc. In a number of works [12-21], many authors have studied the effects of plasma on polymers, finding that significant changes occur in the polymer structure itself when exposed to low-temperature plasma.

The authors of [22] studied propylene plasma treatment to createa hydrophobic surface of ramie to improve its binding to polypropylene (PP); plasma treatment with propane was used in this study. It was found that the wetting angles of the plasma-treated ramie increased from $66.3^{\circ}$ to $106.1^{\circ}$ and the shear strength at the interface with polypropylene increased to $36.4 \%$, which was probably due to an increase in the roughness of the fiber surface. It was also found that propylene plasma treatment is very effective for increasing the carbon content on the surface (from $68.3 \%$ to $82.4 \%$ in $0.5 \mathrm{~min}$ ), and is more effective than propane treatment, although both cases show significant effectiveness of fiber surface modification. It was found that the duration of treatment affects the surface roughness more than its chemical composition, and the optimal time of plasma treatment is within $1 \mathrm{~min}$. It is expected that the modification method developed in this study can be used to modify the fiber surface for various types of natural materials.

The authors of [23] considered wool treatment with low-temperature plasma discharge in order to prevent its shrinkage. During the experiments, woolen fabric was treated with pulsed atmospheric-pressure plasma using a dielectric barrier discharge device from the German Institute of Textile and Fiber Research in Denkendorf by changing the power and air flow. It was found that the studied sample's resistance to shrinkage, coloring ability, and water-absorbing properties increased with an increase in the processing time to $3 \mathrm{~min}$.

In [12], the researchers treated pine and birch surfaces with plasma under low pressure in a radiofrequency (RF) discharge of air, in order to study the wetting and activation of the surface. The effects of plasma treatment on the morphology and wettability of the surfaces were characterized by measurements of the static wetting angle, via infrared spectroscopy with Fourier transform. In the course of the study, a clear increase in the surface energy of wood was observed due to air plasma treatment. The surface hydrophilicity of the samples increased significantly when wood was exposed to a plasma discharge for 5 sor more. As a result, the wettability of the wooden surface increased. A slight decrease in the surface energy of the treated wood after 12 days of aging showed that plasma-induced crosslinking on the wood surface was not the dominant phenomenon.

In [24], an atmospheric plasma discharge was applied to increase the adhesion strength of joints between common beech wood (Fagus sylvatica L.) and metal (steel and aluminum alloy) using four different types of glue. In the course of the research, X-ray photoelectron spectroscopy revealed surface oxidation of all of the materials after plasma treatment-that is, the surface free energy of all of the materials also increased. The study also found that 
plasma treatment increased the shear strength and tensile strength of overlapping joints of wooden elements, wood and steel, as well as wood and aluminum alloys.

In the study of Žigon et al. [25], the wood of spruce and common beech, as well as their thermally modified variations, was plasma-treated. The effects of such treatment on wood coating were studied by evaluating the dynamic wettability and water penetration into the wood. Plasma treatment increased the free surface energy of all wood species, and reduced the marginal wetting angles of the water-based coating, which together indicated an increase in the wettability of the wood after treatment. Finally, it was found that plasma treatment penetrates deeper into beech and unmodified wood than into spruce wood and thermally modified wood.

The authors of [24-27] studied aspen fibers that were activated by plasma to improve the bonds between particles and adhesive for wood composites. The materials were subjected to environmentally friendly dry plasma treatment. After argon, oxygen, or ammonia plasma treatment, aspen fibers were analyzed via X-ray photoelectron (ESCA) and IR (FTIR) spectroscopies methods. The fibers were used to create fiberboard. The properties of aspen wood-fiber-boards were evaluated via mechanical tests and water regain tests. The results showed that the ammonia and oxygen plasma treatment of primary and extracted aspen fiber samples was the most successful for modifying the surface and increasing fiberboard strength.

The works of $[24,25,27,28]$ are also relevant, in which the adhesive properties of adhesives and paints on wood-plastic composites (WPCs) were studied after plasma treatment at atmospheric pressure and ambient air. The surface energy was determined by measuring the contact angle in accordance with the Owens-Wendt approach, and by atomic force microscopy to detect changes in the surface topography. The studies revealed an increase in the polar component of the surface energy and an increase in the surface roughness after plasma treatment, which indicates increased bond strength. These results were confirmed by adhesion strength tests. Tensile adhesion strength tests revealed increased adhesion of water-, solvent- and oil-based paints to plasma-treated surfaces.

Other studies $[25,27,28]$ were aimed at determining the adhesive properties of composites, in which WPCs and continuous fiberglass-reinforced plastic surfaces were treated with forced atmospheric (air) plasma. The fiberglass-reinforced plastic consisted of oriented continuous E-glass fibers in a polypropylene matrix, while the WPC was made using wood flour, polypropylene, and additives. The studies showed that the acid-base component of the surface energy for both WPC and fiberglass-reinforced plastic after plasma treatment correlates with an increase in wettability. X-ray photoelectron spectroscopy was performed on wooden and non-wooden sections of the WPC surfaces; the oxygen concentration increased to a greater extent in non-wooden sections. Measurements of the shear bonding strength showed an increase of $50 \%$ after forced air plasma treatment (FAPT) on WPC surfaces (discharge length 2.5 inches, 1 pass), and up to $200 \%$ for hybrid WPC-FRP. Atomic force microscopy measurements using a probe with a silicon tip showed an increase in adhesive force interactions of up to $56 \%$ on WPC surfaces after FAPT.

In the work of Hazir [29], studies were carried out to improve the characteristics of the coating of heat-treated wood using air plasma treatment. In the studies, two different heat treatment processes were applied to wood samples: A $\left(212^{\circ} \mathrm{C}, 1 \mathrm{~h}\right)$; and $\mathrm{B}\left(212^{\circ} \mathrm{C}\right.$, $2 \mathrm{~h}$ ). According to the method of multicriteria optimization, it was found that the optimal plasma treatment conditions for heat treatment $A$ are a gas flow rate of $60 \mathrm{~mm} / \mathrm{s}$, working distance of $7.69 \mathrm{~mm}$, and pressure of 1 bar. The corresponding values for heat treatment process B were $60 \mathrm{~mm} / \mathrm{s}, 10 \mathrm{~mm}$, and 2 bar.

Therefore, we can say that in recent years, research has been actively conducted in the field of radiofrequency plasma treatment of various surfaces of materials, including wood, for surface modification. However, to date, the possibility of using plasma treatment in the production of glued wooden structures has been understudied. This study aims at improving the adhesive properties of wood by increasing the wettability and adhesive strength of wood during radiofrequency plasma treatment. 


\section{Materials and Methods}

The effect of RF treatment on wood surface was studied on pine samples, since this species is one of the most common in carpentry in Russia. For the research, $230 \times 25 \mathrm{~mm}^{2}$ wood lamellas with a thickness of $10 \mathrm{~mm}$ and a humidity of $6 \% \pm 2 \%$ were prepared.

As already mentioned, one of our main goals was to increase the adhesive qualities of wood. This property is of great importance in the production of large-span laminated wooden structures. To solve this problem, studies were conducted on the modification of wood using a radiofrequency induction plasma discharge unit (Figure 1). The samples were treated via the jet method. When high-frequency voltage 1 is applied to the inductors in discharge chamber 2, a plasma stream is formed due to heating of the plasma-forming gas to the plasma state, which flows out of the plasma torch in the form of plasma jet 3 .

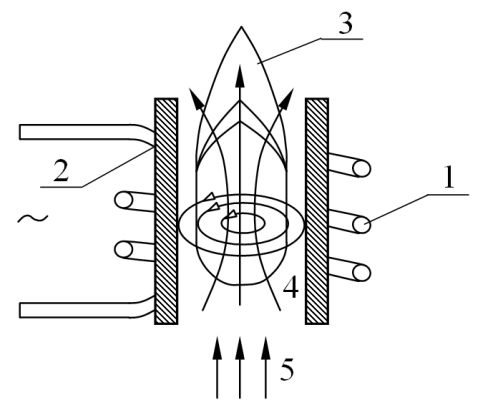

Figure 1. Schematic diagram of a high-frequency induction plasma torch: 1-inductor; 2-discharge chamber; 3-plasma jet; 4-discharge area; 5-gas flow.

To study RF discharge treatment, radiofrequency generator 1 was used, tuned to an induction load (Figure 2). The generator was assembled according to a single-circuit scheme with a common cathode. The proposed scheme, equipped with devices for monitoring, signaling, adjustment, and protection, allows the reduction of energy consumption for plasma treatment, and makes it possible to control the treatment modes. RF generator 1 outputs an RF discharge at a frequency of $1.76 \mathrm{MHz}$. Appearance of the experimental RF plasma unit is shown in Figure 3.

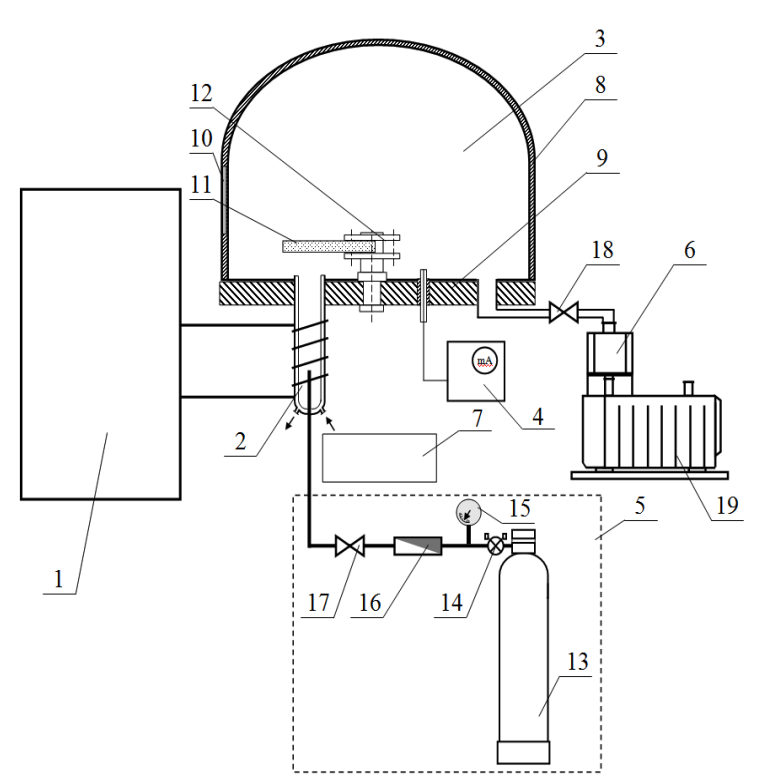

Figure 2. Pilot RF plasma unit operation flowchart: 1-radiofrequency generator; 2 -radiofrequency plasma torch; 3-operation chamber; 4-diagnostic monitoring equipment; 5-plasma gas supply control system; 6-a pumping system; 7-water supply systems; 8-metal cap; 9-plate; 10-viewing window; 11-test material; 12-stationary device (carousels); 13-pressure gas cylinder; 14-reducer; 15-pressure gauge; 16-rotameter; 17-needle leak; 18-valve; 19-pump. 
RF plasma torch discharge chamber 2 is made of quartz, due to its good optical transparency, sufficient heat resistance, and mechanical strength.

Plasma gas is supplied to operation chamber 3 through plasma torch 2. The operation chamber is composed of metal cap 8 mounted on plate 9 . Plate 9 has a number of holes of various diameters for mounting the plasma torch, diagnostic tools, and auxiliary devices, as well as for pumping the medium out of the operation chamber. Viewing window 10 is provided in metal cap 8 for visual process control. Test material 11 is fixed in a special stationary device (carousel) 12 mounted on plate 9.

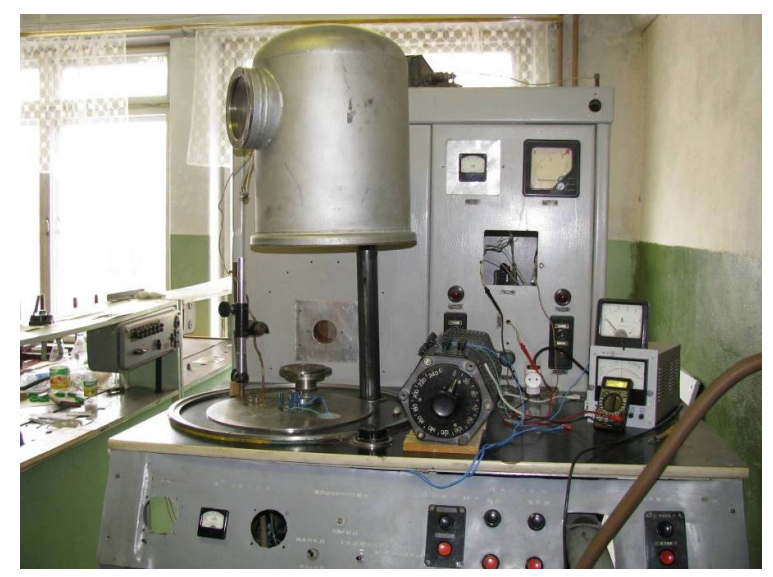

Figure 3. Appearance of the experimental RF plasma unit.

Plasma gas supply system 5 consists of operation chamber 3 of a device for producing gas mix, pressure gas cylinder 13 , reducer 14 , pressure gauge 15 , rotameter 16 for metering gas flow, needle leak 17 for flow control, valve 18, which connects the internal space with the vacuum system, and pump 19. Preset thermal conditions of the unit's parts and assemblies are maintained by water supply system 7 . Water is supplied through the temperature control systems of the most thermally loaded elements: the generator lamp, inductor, and discharge chamber.

Wood samples were treated in radiofrequency induction discharge plasma with the following output parameters: generation frequency $1.76 \mathrm{MHz}$, duration of sample treatment up to $15 \mathrm{~min}$, flow rate of plasma gas $G=0.04 \mathrm{~g} / \mathrm{s}$, operating voltage at anode $\mathrm{Ua}=1.5-7.5 \mathrm{kV}$, and current at anode Ia $=0.3-0.8 \mathrm{~A}$. Argon, air, and a mixture of propane and nitrogen were used as the plasma gases.

For RF discharge treatment, the samples were placed in the vacuum chamber of the unit and fixed in device 12. Then, the air was pre-pumped out of the vacuum chamber, after which the working gas was supplied. Pressure was set by the valve connecting the vacuum chamber to the vacuum unit.

After treatment, the samples were kept in room conditions for $4 \mathrm{~h}$ to equalize their humidity.

To determine marginal wetting angle $\theta$, the sessile drop method was used. In this method, the angle between the solid surface and the liquid at the contact point of the three phases is measured.

To determine the effect of RF plasma treatment on the effectiveness of capillary impregnation, the penetration depth of protective compounds into wood was studied. Water-based and oil-based antiseptics were used as impregnating agents. The liquids were applied to the wood surface. After the impregnating agents dried up completely, the samples were split along the fibers, and the depth of impregnation was measured using an optical microscope.

In addition, the material samples were examined for adhesive interaction of glue and wood using a Konstanta AC adhesion gauge, by fixing the control stop perpendicular to the coating surface. Three types of glue were used as adhesives: PVA-based glue, 
polyurethane-based glue, and urea-formaldehyde resin. Upon curing of the adhesive, the test device was attached to the stop and installed in such a way that the tensile load was applied perpendicular to the surface being tested (Figure 4).

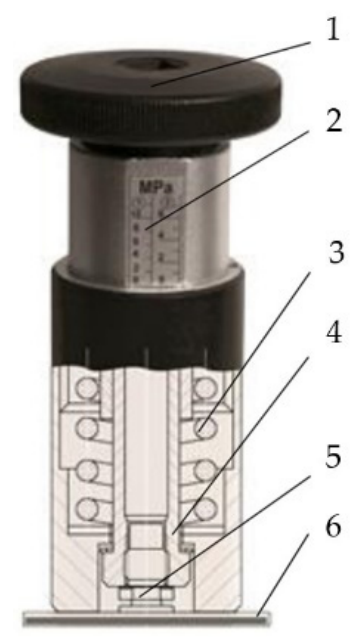

Figure 4. Konstanta AC adhesion gauge: 1-upper handle; 2-scale; 3-spring; 4-grip; 5mushroom knob; 6-coating.

The effect of RF plasma treatment on adhesion processes was studied by determining the bending strength of the laminated beam (Figure 5). For testing, the beams were made by gluing together RF-plasma-treated lamellae. The reference beams were made from ordinary wood.

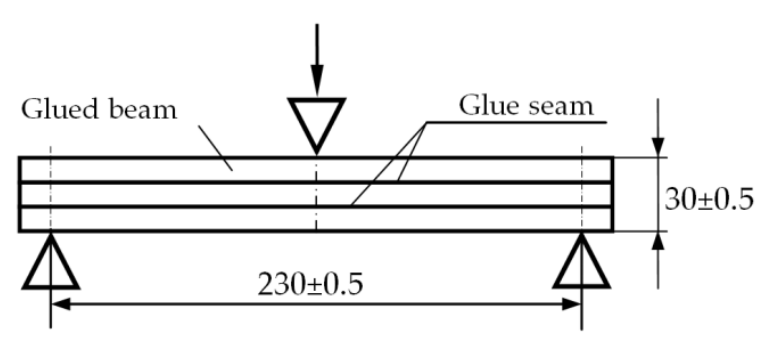

(a)

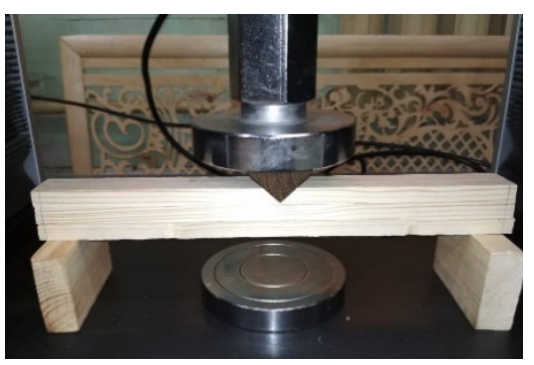

(b)

Figure 5. Bending tests: (a)—scheme of determining the bending strength of the laminated beam; (b) - photo of determining the bending strength of the laminated beam.

The strength under static bending was determined by the formula:

$$
\sigma=\frac{1.5 P_{\max } l}{b h^{2}}
$$

where $P_{\max }$ is the maximum breaking load $(\mathrm{N}) ; l$ is the distance between the supports $(\mathrm{mm})$; $b$ and $h$ are the width and height of the sample, respectively $(\mathrm{mm})$.

Statistical processing of the study outcome was facilitated using the Statistica 8.0 software package. The results are presented in the form of an average value and a confidence interval. The relative error of the research results was determined by the mean squared deviation and Student's criterion $t_{s}\left(t_{s}=3.2\right)$ for a confidence probability of 0.95 and a sample equal to 4 .

\section{Results}

The results of the study of changes in the marginal wetting angle of wood depending on the duration of reduced-pressure RF plasma treatment in three plasma gases (argon, 
propane/nitrogen, and air) are shown in Figure 6. The experiments were carried out within $1 \mathrm{~h}$ after RF plasma treatment.

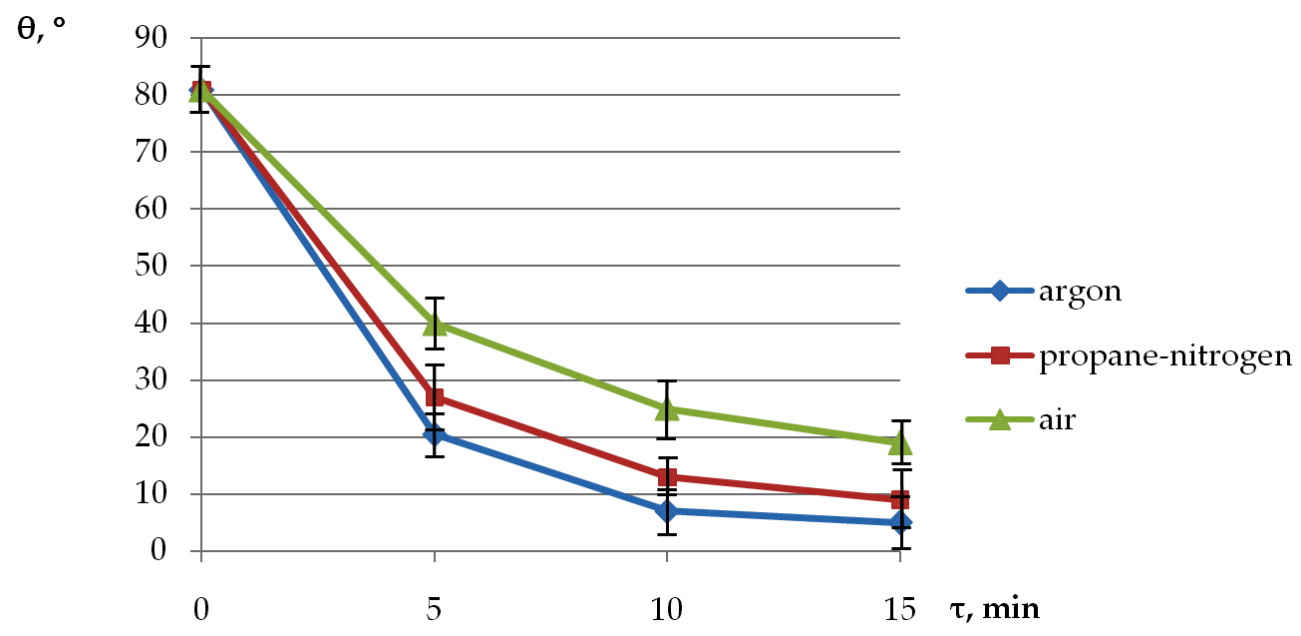

Figure 6. Change in the marginal wetting angle of samples with different plasma gases: $\tau=15 \mathrm{~min}$; $\mathrm{G}=0.04 \mathrm{~g} / \mathrm{s} ; \mathrm{Ua}=4.5 \mathrm{kV} ; \mathrm{Ia}=0.9 \mathrm{~A}$.

It was established that the exposure time affects the change in the marginal wetting angle. The greatest effect was achieved in the first $5 \mathrm{~min}$ of treatment; a further increase in treatment duration did not provide a significant effect. The greatest decrease in the marginal wetting angle was provided by RF argon plasma treatment. Hence, argon was used as a plasma gas for further research.

Furthermore, the effect of the plasma torch's operational power on the marginal wetting angle of the samples was determined for the same duration of RF plasma treatment, i.e., $5 \mathrm{~min}$. Figure 7 shows the effects of changes in individual parameters of the plasma torch's power-voltage and current-on the wettability of the treated samples. In Figure 7a, a graphical dependence of the wetting angle on the change in current strength at a constant mains voltage $(\mathrm{Ua}=7.5 \mathrm{kV})$ is obtained. The graph of the influence of voltage changes on the contact angle at a fixed current strength $(\mathrm{Ia}=0.8 \mathrm{~A})$ is shown in Figure $7 \mathrm{~b}$.

It was established that voltage has a greater effect on treatment efficiency than current. A threefold increase in current provided an increase in the marginal wetting angle from $81^{\circ}$ to $38^{\circ}$, i.e., by $53.1 \%$. A threefold increase in voltage provided an decrease in the marginal wetting angle from $81^{\circ}$ to $21^{\circ}$, i.e., by $74.1 \%$.

The combined effect of the two parameters is reflected in the curve in Figure 8. The graph shows that an increase in the treatment power helps reduce the marginal wetting angle to $17^{\circ}$.

An increase in the wettability of wood provides an increase in the depth of liquid penetration, which is confirmed by the results of experimental studies to determine the impregnation depth, as shown in Table 1. The above data show that RF plasma treatment of wood contributes to an increase in the penetration depth of the impregnating substance. Moreover, taking into account the relative error of $5.9 \%$ with a confidence interval of 0.95 , it should be noted that for water-based antiseptics, the use of RF treatment allowed an increase in the impregnation efficiency by $121.4 \%$, and for oil-based antiseptics by $109.1 \%$. Therefore, the antiseptic impregnation depth after RF treatment more than doubled in relation to the reference sample. 


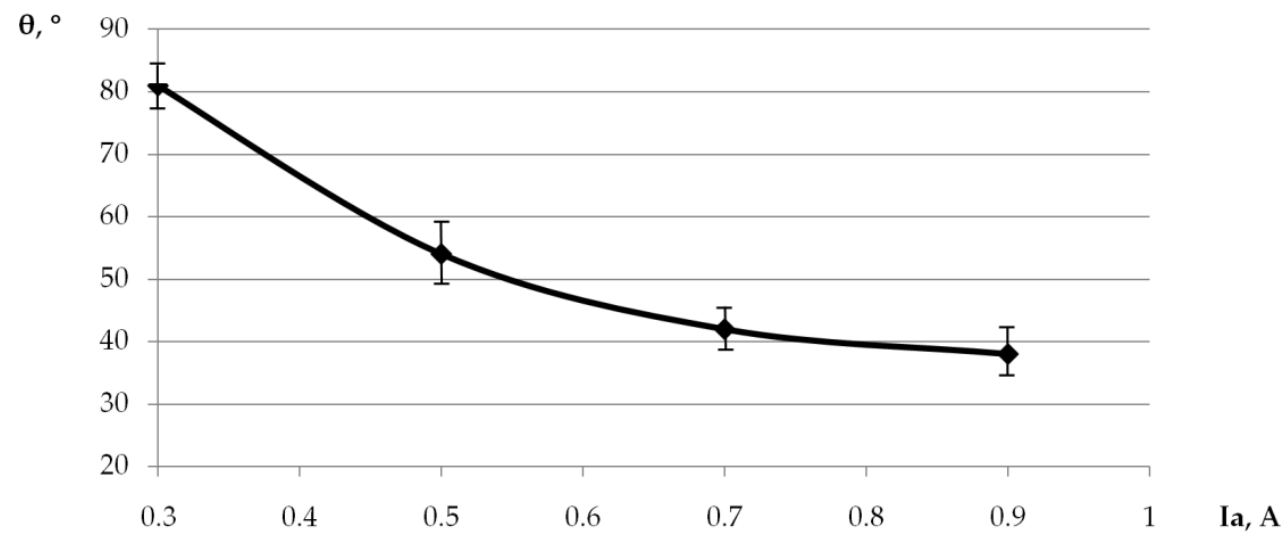

(a)

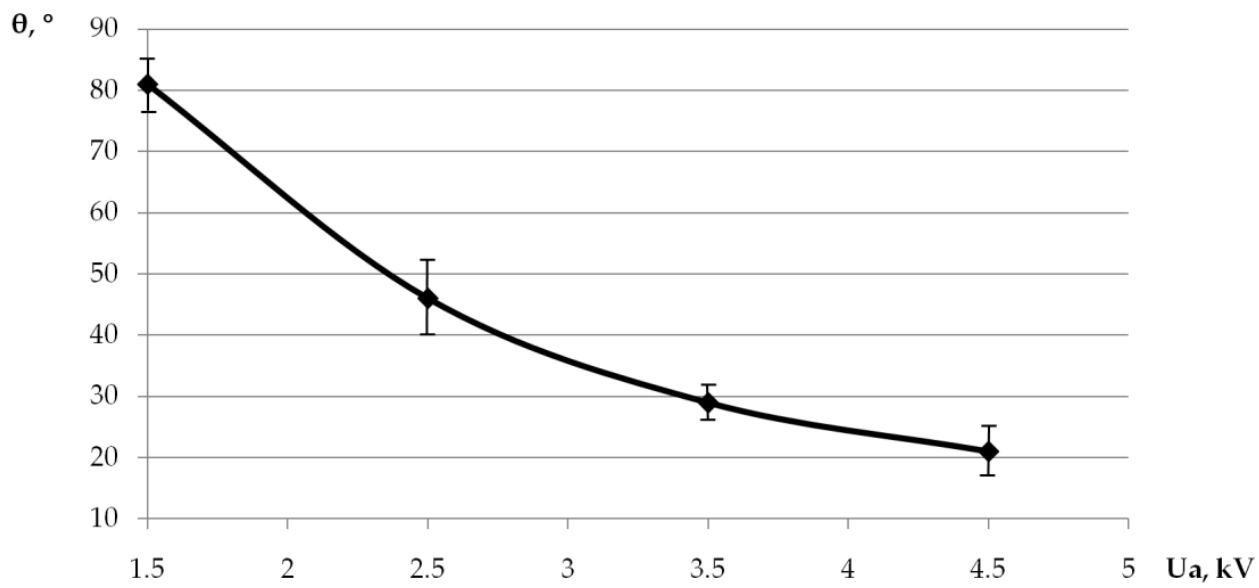

(b)

Figure 7. Dependence of the marginal wetting angle of wood samples treated with low-pressure RF plasma on (a) anode voltage at the (Ua, kV); and (b) anode current (Ia, A).

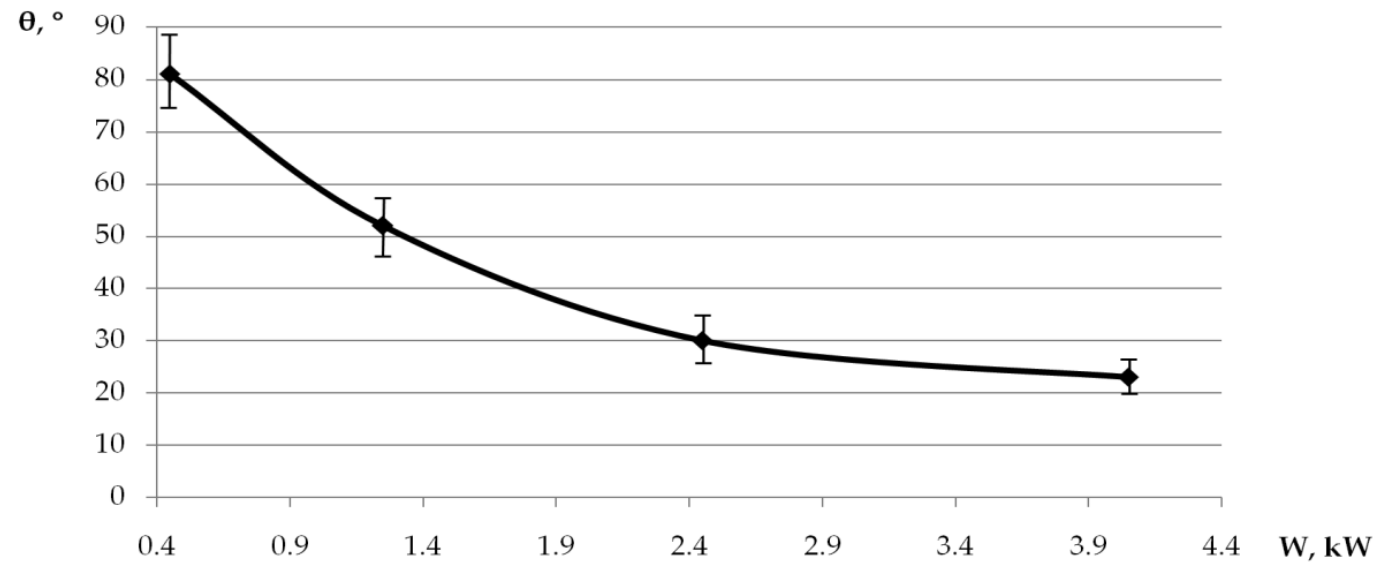

Figure 8. Influence of RF plasma treatment power on the marginal wetting angle of wood. 
Table 1. Determination of impregnation depth.

\begin{tabular}{ccccc}
\hline \multirow{2}{*}{ Impregnating Liquid } & \multicolumn{2}{c}{ Depth of Impregnation, mm } & \multirow{2}{*}{$\boldsymbol{\Delta} \boldsymbol{~}$ Discrepancy, \% } \\
\cline { 2 - 4 } & Reference Sample & RF-Treated Sample & & \\
\hline Water-based antiseptic & 1.4 & 3.1 & 1.7 & 121.4 \\
Oil-based antiseptic & 1.1 & 2.3 & 1.2 & 109.1 \\
\hline
\end{tabular}

The impregnation depth of the water-based antiseptic after RF treatment increased by more than double in relation to the reference sample. For oil-based antiseptics, RF treatment provided an increase in the impregnation efficiency by $109.1 \%$.

Furthermore, the adhesive strength of the adhesive composition on the wood surface was studied, as shown in Table 2. Three types of wood glue were used as adhesives: PVAbased glue, polyurethane-based glue, and urea-formaldehyde resin. With a probability of 0.95 , RF plasma treatment improved the adhesion of glues to the wood surface by $18 \%$ for polyurethane glue, and 31\% for PVA-based adhesives. Urea-formaldehyde resin also showed an increase in adhesive strength, by $26 \%$ compared to the reference sample. The relative error of the studies is $6.4 \%$. The results obtained are consistent with the studies [12].

Table 2. Comparative analysis of the adhesive strength of wood.

\begin{tabular}{ccccc}
\hline \multirow{2}{*}{ Adhesive } & \multicolumn{2}{c}{ Adhesive Strength $\boldsymbol{\sigma}, \mathbf{M P a}$} & \multirow{2}{*}{$\boldsymbol{D} \boldsymbol{\text { Discrepancy, } \%}$} \\
\cline { 2 - 4 } & Reference Sample & RF-Treated Sample & & \\
\hline PVA-based glue & 4.9 & 6.4 & 1.5 & 31 \\
Polyurethane-based glue & 6.7 & 7.9 & 1.2 & 18 \\
Urea-formaldehyde resin & 8.3 & 10.5 & 2.2 & 26 \\
\hline
\end{tabular}

Figure 9 shows a diagram of the change in the strength of a laminated beam at static bending, depending on the type of adhesive. The diagram shows that RF treatment causes an increase in the bending strength of the laminated beam, which is explained both by an increase in the adhesion efficiency and by partial effective impregnation of the glued lamellae with the formation of composite wood. Taking into account measurement errors with a probability of 0.95 , it can be assumed that with the use of PVA-based glue, the strength of laminated beams increases by $15 \%$ relative to the control sample, with the use of polyurethane-based glue, by $8 \%$, and with urea-formaldehyde resin, by $9 \%$. The relative error of the studies is $3.8 \%$.

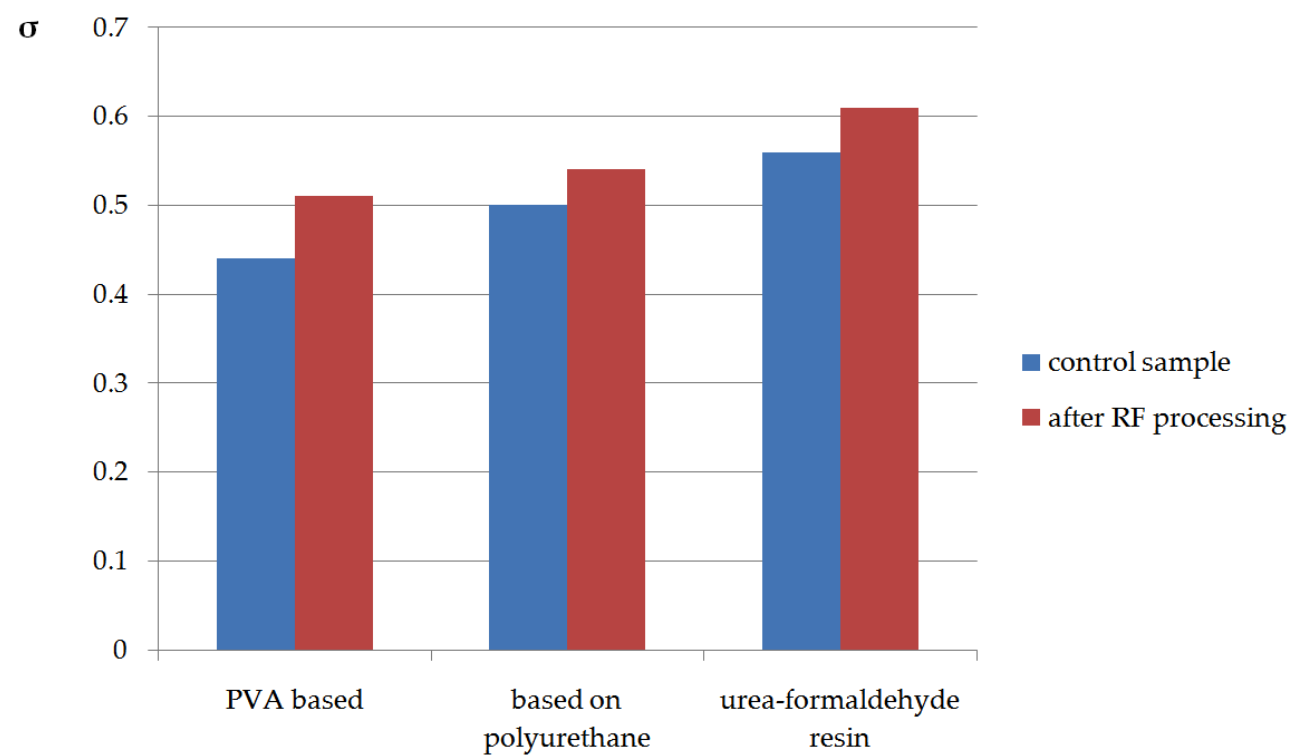

Figure 9. Bending strength depending on the type of adhesive. 
The strength of laminated beams using a PVA-based glue increased by $15 \%$ compared to the reference sample; using a PU-based glue, by $8 \%$; and using urea-formaldehyde resin, by $9 \%$.

Therefore, the investigated process of RF plasma treatment of wood can be used in the production of large-span laminated wooden structures, in order to increase their bearing capacity while maintaining dimensional characteristics.

\section{Conclusions}

Our study revealed that RF plasma treatment increases the wettability of the wood surface. The factors influencing the treatment efficiency are the power of the RF plasma torch and the duration of treatment. The greatest effect is achieved in the first 5 min of treatment, with a total power of $4.05 \mathrm{~kW}$; a further increase in treatment duration does not provide a significant effect.

It was found that RF plasma treatment in argon and its mixtures causes an increase in the wettability of wood by an average of $5 \%$ compared with RF plasma treatment in air or in a propane/nitrogen mixture.

It was found that RF plasma pretreatment of the wood surface affects the performance of adhesion to the wood surface, increasing its surface energy values and the nature of the adhesive interaction in the "glue-wood" system, thereby increasing the strength characteristics of the glued products. At the same time, a significant effect on the strength of glued products was observed when using PVA-based glue, compared to the use of polyurethane-based adhesives and urea-formaldehyde resin.

Thus, in connection with the research results, an improved production process of glued wooden structures is proposed, in which lamellae are treated with radiofrequency plasma on both sides along the glued layers, which will ensure high adhesion strength.

Author Contributions: Conceptualization, R.R.S.; methodology, R.R.S. and R.S.; software, S.M. and R.K.; validation, R.R.S. and N.G.; formal analysis, R.S.; investigation, R.R.S., R.K. and N.G.; resources, S.M.; data curation, S.M. and R.S.; writing-original draft preparation, N.G.; writing-review and editing, N.K.; visualization, S.M.; supervision, A.S.; project administration, R.K.; funding acquisition, S.M. All authors have read and agreed to the published version of the manuscript.

Funding: This work was supported by a grant from the President of the Russian Federation to support at the national level young Russian scientists who have a Ph.D. degree (MK-2246.2020.8).

Institutional Review Board Statement: Not applicable.

Informed Consent Statement: Not applicable.

Data Availability Statement: Not applicable.

Conflicts of Interest: The authors declare no conflict of interest.

\section{References}

1. Safin, R.; Barcík, Š.; Shaikhutdinova, A.; Kaynov, P.; Razumov, E. Development of the energy-saving technology of thermal modification of wood in saturated steam. Acta Fac. Xylologiae 2015, 57, 39-47.

2. Safin, R.R.; Khasanshin, R.R.; Mukhametzyanov, S.R. Influence of technical parameters of disk-shaped reactor on productivity of heat treatment of crushed wood. IOP Conf. Ser. Mater. Sci. Eng. 2018, 327, 042095. [CrossRef]

3. Safin, R.R.; Talipova, G.A.; Galyavetdinov, N.R.; Nazipova, F.V.; Salimgaraeva, R.V. The study of the destructive properties of wood-filled composites for the production of biodegradable packaging materials. In Proceedings of the 19th International Multidisciplinary Scientific Geoconference, SGEM, Albena, Bulgaria, 30 June 2019; Volume 19, pp. 541-546.

4. Khasanshin, R.R.; Safin, R.R.; Galyavetdinov, N.R. Use of low-grade vegetable raw materials in production of composites by preliminary processing. Solid State Phenom. 2017, 265, 296-302. [CrossRef]

5. Marjan, A.; Mohammad, K.S.; Amir, H.S.; Mina, A. Wood surface functionalization by means of low-pressure air plasma. Radiat. Eff. Defects Solids 2012, 167, 814-825.

6. Manolache, S.; Jiang, H.; Rowell, R.M.; Denes, F.S. Hydrophobic wood surfaces generated by non-equilibrium, atmospheric pressure (NEAPP) plasma-enhanced coating. Mol. Cryst. Liq. Cryst. 2008, 483, 348-351. [CrossRef]

7. Avramidis, G.; Hauswald, E.; Lyapin, A.; Militz, H.; Viöl, W.; Wolkenhauer, A. Plasma treatment of wood and wood-based materials to generate hydrophilic or hydrophobic surface characteristics. Wood Mater. Sci. Eng. 2009, 4, 52-60. [CrossRef] 
8. Wolkenhauer, A.; Avramidis, G.; Hauswald, E.; Militz, H.; Viöl, W. Plasma treatment of wood-plastic composites to enhance their adhesion properties. J. Adhes. Sci. Technol. 2008, 22, 2025-2037. [CrossRef]

9. Cademartori, P.H.G.; Junior, L.R.S.; Blanchet, P.; Magalhães, W.L.E.; Muniz, G.I.B. The use of low-pressure plasma on enhancing the attachment of Al2O3 nanoparticles to wood-plastic composites. J. Wood Chem. Technol. 2018, 38, 71-83. [CrossRef]

10. Macedo, M.J.P.; Mattos, A.L.A.; Costa, T.H.C.; Feitor, M.C.; Ito, E.N.; Melo, J.D.D. Effect of cold plasma treatment on recycled polyethylene/kapok composites interface adhesion. Compos. Interfaces 2019, 26, 871-886. [CrossRef]

11. Owens, D.K.; Wendt, R.C. Estimation of the surface free energy of polymers. J. Appl. Polym. Sci. 1969, 13, 1741-1747. [CrossRef]

12. Hazir, E.; Seker, S.; Koc, K.H.; Dilik, T.; Erdinler, E.S.; Ozturk, E. Optimization of plasma treatment parameters to improve the wood coating adhesion strength using Taguchi integrated desirability function approach. J. Adhes. Sci. Technol. 2021, 35, 451-467. [CrossRef]

13. Gupta, B.S.; Laborie, M.P.G. Surface activation and adhesion properties of wood-fiber reinforced thermoplastic composites. J. Adhes. 2007, 83, 939-955. [CrossRef]

14. Huang, H.; Wang, B.J.; Dong, L.; Zhao, M. Wettability of hybrid poplar veneers with cold plasma treatments in relation to drying conditions. Dry. Technol. 2011, 29, 323-330. [CrossRef]

15. Bell, A.T. Introduction to plasma processing. Solid State Technol. 1978, 21, 89-94.

16. Boundur, J.A. Dry process techcology (RIE). J. Vac. Sci. Technol. 1976, 13, 1023-1029.

17. Craighead, H.G. Textured thin film Si solar absorbers using reactive ion etching. J. Appl. Phys. Lett. 1980, 37, 653-655. [CrossRef]

18. Tatoulian, M.; Cavalli, F.; Lorang, G.; Amouroux, J.; Arefi-Khonsari, F. Improved adhesion between plasma-treated fluorinated and evaporated copper. In Proceedings of the 14th International Symposium on Plasma Chemistry, Prague, Czech Republic, 2-6 August 1999; pp. 1785-1789.

19. Ricard, A. Plasma Surface Interactions and Processing of Materials; Kluwer Academic Publishers: Dordrecht, The Netherlands, 1990; p. 557.

20. Stefeska, M.; Rahel, J.; Cernak, M.; Hudes, I.; Micula, M.; Mazur, M. Atmospheric-pressure plasma treatment of ultrahigh molecular weight polyethylene fibres. In Proceedings of the 14th International Symposium on Plasma Chemistry, Prague, Czech Republic, 2-6 August 1999; Volume 3, pp. 1251-1254.

21. Zhang, Q.; Jiang, Y.; Yao, L.; Jiang, Q.; Qiu, Y. Hydrophobic surface modification of ramie fibers by plasma-induced addition polymerization of propylene. J. Adhes. Sci. Technol. 2015, 29, 691-704. [CrossRef]

22. Totolin, V.; Manolache, S.; Rowell, R.M.; Denes, F.S. Application of cold plasma to improve properties of phenolic-bonded aspen fiberboard. J. Nat. Fibers 2008, 5, 170-192. [CrossRef]

23. Mori, M.; von Arnim, V.; Dinkelmann, A.; Matsudaira, M.; Wakida, T. Modification of wool fibers by atmospheric pressure plasma treatment. J. Text. Inst. 2011, 102, 534-539. [CrossRef]

24. Žigon, J.; Kovač, J.; Zaplotnik, R.; Saražin, J.; Šernek, M.; Petrič, M.; Dahle, S. Enhancement of strength of adhesive bond between wood and metal using at-mospheric plasma treatment. Cellulose 2020, 27, 6411-6424. [CrossRef]

25. Žigon, J.; Pavlič, M.; Kibleur, P.; Van den Bulcke, J.; Petrič, M.; Van Acker, J.; Dahle, S. Treatment of wood with atmospheric plasma discharge: Study of the treatment process, dynamic wettability and interactions with a waterborne coating. Holzforschung 2021, 75, 603-613. [CrossRef]

26. Safin, R.R.; Khasanshin, R.R.; Mukhametzyanov, S.R. Influence of technical parameters of disk-shaped reactor on productivity of heat treatment of crushed wood. In Proceedings of the IOP Conference Series: Materials Science and Engineering 11th International Conference on Mechanical Engineering, Automation and Control Systems, MEACS 2017, Tomsk, Russia, 4-6 December 2017; p. 135857.

27. Ivanov, I.; Gospodinova, D.; Dineff, P.; Veleva, L. Plasma surface technology promoting capillary impregnation of wood: Xps analysis of different plasma pre-treated wood surfaces. Mach. Technol. Mater. 2014, 8, 2-11.

28. Oporto, G.S.; Gardner, D.J.; Bernhardt, G.; Neivandt, D.J. Forced air plasma treatment (FAPT) of hybrid wood plastic composite (WPC)-fiber reinforced plastic (FRP) surfaces. Compos. Interfaces 2009, 16, 847-867. [CrossRef]

29. Hazir, E. Improvement of heat-treated wood coating performance using atmospheric plasma treatment and design of experiments method. Polymers 2021, 13, 1520. [CrossRef] [PubMed] 